\title{
Loss of $\beta$-catenin triggers oxidative stress and impairs hematopoietic regeneration
}

\author{
William Lento, ${ }^{1,2,3,4}$ Takahiro Ito, ${ }^{1,2}$ Chen Zhao, ${ }^{3}$ Jeffrey R. Harris, ${ }^{4}$ Wei Huang, ${ }^{4}$ Chen Jiang, ${ }^{5}$ \\ Kouros Owzar, ${ }^{5}$ Sadhna Piryani, ${ }^{4}$ Luigi Racioppi, ${ }^{4,6}$ Nelson Chao, ${ }^{4}$ and Tannishtha Reya ${ }^{1,2,3,7,8}$ \\ ${ }^{1}$ Department of Pharmacology, University of California at San Diego School of Medicine, La Jolla, California 92093, USA; \\ ${ }^{2}$ Sanford Consortium for Regenerative Medicine, La Jolla, California 92093, USA; ${ }^{3}$ Department of Pharmacology and Cancer \\ Biology, ${ }^{4}$ Department of Medicine, Division of Hematological Malignancies and Cellular Therapy, ${ }^{5}$ Department of Biostatistics \\ and Bioinformatics, Duke University Medical Center, Durham, North Carolina 27710, USA; ${ }^{6}$ Department of Molecular \\ Medicine and Medical Biotechnology, University of Naples Federico II, Naples 80131, Italy; ${ }^{7}$ Moores Cancer Center, University \\ of California at San Diego School of Medicine, La Jolla, California 92093, USA
}

Accidental or deliberate ionizing radiation exposure can be fatal due to widespread hematopoietic destruction. However, little is known about either the course of injury or the molecular pathways that regulate the subsequent regenerative response. Here we show that the Wnt signaling pathway is critically important for regeneration after radiation-induced injury. Using Wnt reporter mice, we show that radiation triggers activation of Wnt signaling in hematopoietic stem and progenitor cells. $\beta$-Catenin-deficient mice, which lack the ability to activate canonical Wnt signaling, exhibited impaired hematopoietic stem cell regeneration and bone marrow recovery after radiation. We found that, as part of the mechanism, hematopoietic stem cells lacking $\beta$-catenin fail to suppress the generation of reactive oxygen species and cannot resolve DNA double-strand breaks after radiation. Consistent with the impaired response to radiation, $\beta$-catenin-deficient mice are also unable to recover effectively after chemotherapy. Collectively, these data indicate that regenerative responses to distinct hematopoietic injuries share a genetic dependence on $\beta$-catenin and raise the possibility that modulation of Wnt signaling may be a path to improving bone marrow recovery after damage.

[Keywords: Wnt signaling; $\beta$-catenin; hematopoietic stem cells; oxidative stress; regeneration]

Supplemental material is available for this article.

Received October 1, 2013; revised version accepted March 26, 2014.

Hematopoietic stem cell (HSC) transplantation is used to treat hematological malignancies, autoimmune disorders, and immunodeficiencies (Roncarolo et al. 2011). Myeloablative regimens can use total body irradiation, which is administered as a series of fractionated treatments totaling $1200-1350$ centigrays (cGy). This conditioning accomplishes several objectives simultaneously: Immune system ablation reduces the likelihood of graft rejection, provides bone marrow space for the donor graft expansion, and destroys aberrant or leukemic host cells. While radiation and transplantation have improved clinical therapies, treatment outcome is limited by the rapidity with which donor engraftment occurs. A protracted pancytopenia increases the risk of bleeding and multiple infections (Neven et al. 2009). At present, however, few clinical strategies exist to enhance engraftment and recovery in vivo, and current therapy with granulocyte colony-stimulating factor has only marginal

${ }^{8}$ Corresponding author E-mail treya@ucsd.edu

Article is online at http://www.genesdev.org/cgi/doi/10.1101/gad.231944.113. success at improving engraftment (Kawano et al. 1998; Ojeda et al. 1999; Canales and Hernandez-Navarro 2004). Therefore, a clear understanding of the impact of radiation injury and the molecular pathways that endogenously regulate regeneration is essential to devising new approaches for accelerating stem cell engraftment and hematopoietic recovery.

We focused on defining the microenvironmental cues that may contribute to regeneration following radiation and studied Wnt signaling as a potential regulator of this process in vivo. The canonical Wnt pathway leads to the accumulation and nuclear localization of $\beta$-catenin, which can then interact with members of the T-cell factor/lymphoid enhancer-binding factor (Tcf/Lef) family of DNA-binding proteins to activate transcription of Wnt target genes (Mulroy et al. 2002). While Wnt signaling has

(C) 2014 Lento et al. This article is distributed exclusively by Cold Spring Harbor Laboratory Press for the first six months after the full-issue publication date (see http://genesdev.cshlp.org/site/misc/terms.xhtml). After six months, it is available under a Creative Commons License (Attribution-NonCommercial 4.0 International), as described at http:// creativecommons.org/licenses/by-nc/4.0/. 
been implicated in certain types of regeneration, such as after fin amputation in zebrafish and limb regeneration in adult axolotl (Kawakami et al. 2006), the precise role of Wnt signaling in mammalian hematopoietic regeneration after cytotoxic injury is unclear.

To determine whether Wnt signaling is required for effective regeneration, we first analyzed TCF/Lef H2BGFP reporter mice after systemic bone marrow injury and found that Wnt signaling was rapidly induced during regeneration in long-term HSCs and progenitors. Furthermore, the analysis of conditional $\beta$-catenin-deficient mice demonstrated that the loss of Wnt signaling dramatically impaired the recovery of HSCs, progenitors, and bone marrow following radiation injury. At a molecular level, radiation exposure in the absence of $\beta$-catenin caused a decreased expression of the hydrogen peroxide $\left(\mathrm{H}_{2} \mathrm{O}_{2}\right)$ detoxifying enzyme catalase and led to the accumulation of reactive oxygen species (ROS) and superoxide $\left(\mathrm{O}_{2}{ }^{-}\right)$free radicals in stem cells and an inability to repair DNA damage. Finally, we show that $\beta$-catenin plays a more general role in regeneration following distinct hematopoietic injuries. Exposure to the chemotherapeutic agent 5fluorouracil (5-FU) led to impaired bone marrow recovery and a lethal hematopoietic failure in $\beta$-catenin ${ }^{-/-}$mice. Collectively, our data suggest that $\beta$-catenin is critical for hematopoietic regeneration in response to a broad range of injuries in vivo.

\section{Results}

Kinetics of hematopoietic regeneration following radiation injury

Despite the fact that radiation injury occurs frequently in the course of clinical therapy, there is little understanding of the temporal nature of the injury and the specific signals that mediate hematopoietic recovery in vivo. To address these issues, we first analyzed the kinetics of regeneration following a range of radiation doses; specifically, a variety of indicators of recovery, including peripheral blood cell and HSC counts and the cell cycle status of HSCs, was comprehensively tracked by examining whole bone marrow after 2.5 Gy, 4.5 Gy, or 6.5 Gy $\gamma$-irradiation exposure (single fraction) (Supplemental Fig. S1A-C). Whole bone marrow cell counts returned to normal within $30 \mathrm{~d}$ of exposure to $2.5 \mathrm{~Gy}$ and within $90 \mathrm{~d}$ of exposure to $4.5 \mathrm{~Gy}$ and 6.5 Gy. Peripheral blood analysis conducted by automated complete blood cell count (Supplemental Fig. S1D-F) indicated that the repopulation of total white blood cells was complete within $90 \mathrm{~d}$, although certain subsets such as platelets, neutrophils, and red blood cells recovered with different kinetics (data not shown).

We also evaluated the kinetics of stem cell regeneration directly by analyzing the c-Kit ${ }^{+}$lineage ${ }^{-} \mathrm{Sca}-1^{+} \mathrm{CD} 34^{-}$ $\left(\mathrm{KLS} 4^{-}\right)$population at each radiation dose (Supplemental Fig. S1G). The stem and progenitor cell pools remained significantly reduced compared with controls from day 7 post-injury to beyond day 60 following 4.5 Gy (Supplemental Fig. S1G-H). In addition, stem cells in irradiated mice showed a reduced frequency of cells in G0/G1 and an increased frequency of cells in both the S phase and G2-M phases from day 7 to 30 after exposure to $4.5 \mathrm{~Gy}$. Interestingly our analyses indicate that surviving stem cells are only transiently induced into cycle and then regain normal cell cycle characteristics (Supplemental Fig. S1I-K). The generation of the basic cellular and temporal profile of regeneration indicated that use of $4.5 \mathrm{~Gy}$ as a trigger would provide a tractable system for studying the molecular signaling events activated during regeneration; at other radiation doses, the injury may be either too mild or too severe to observe responses to signal modulation.

\section{Wnt signaling is activated after radiation injury in vivo}

Although Wnt signaling has been examined in the context of regeneration in other tissues and model organisms, its genetic requirement in regeneration following hematopoietic injury remains unknown. To determine whether regeneration involves Wnt signaling, we first examined activation of the pathway by analyzing a TCF H2B-GFP Wnt reporter mouse (Ferrer-Vaquer et al. 2010), in which the $6 \mathrm{x}-\mathrm{TCF} /$ Lef-binding promoter drives expression of the histone H2B-GFP fusion protein in response to Wnt signaling. Under homeostatic conditions, the reporter was active in $1.6 \%$ of bone marrow stem and progenitor cells (KLS), with a background signal of $<0.5 \%$. GFP expression in TCF H2B-GFP bone marrow was also confirmed using immunofluorescence staining of bone sections (Supplemental Fig. S2B). Importantly, reporter activity was sharply up-regulated following radiation injury, with a 12 -fold increase in the frequency of reporter-positive HSCs (KLS150 $48^{-}$) by day 14 after radiation (Fig. 1A,B). Reporter signal returned toward baseline by day 28 . These data were also confirmed by analyzing the expression of nonphosphorylated nuclear $\beta$-catenin (Fig. 1C). Importantly, induction of Wnt reporter activity was also observed after exposure to the chemotherapeutic agent 5-FU (Supplemental Fig. S2E). Consistent with the more rapid regeneration after 5-FU (Venezia et al. 2004), reporter activity was induced in stem and progenitor cells as early as $3 \mathrm{~d}$ after exposure and returned to baseline by day 14 . Finally, limited Wnt reporter activation also occurred in granulocyte-macrophage progenitor cells (Supplemental Fig. S2C) and mature T cells (Supplemental Fig. S2D) following injury, but the relevance of this activation remains to be investigated.

To determine whether the activation of Wnt signaling may be ligand-driven, we tested whether Wnt ligand expression changed during regeneration. To this end, we examined the expression of several candidate Wnts in bone marrow sections following radiation exposure. Neither Wnt3a nor Wnt5a showed substantial changes in expression at $7 \mathrm{~d}$ post-radiation (Supplemental Fig. S2A; data not shown). However, we detected a clear rise in the expression of Wnt10b after radiation (Fig. 1D); this increase was further confirmed by Western blot analysis (Fig. 1E). Thus, the activation of Wnt reporter activity together with the up-regulation of Wnt ligand collectively indicated that Wnt signaling may be an essential element of regeneration after injury. 
A
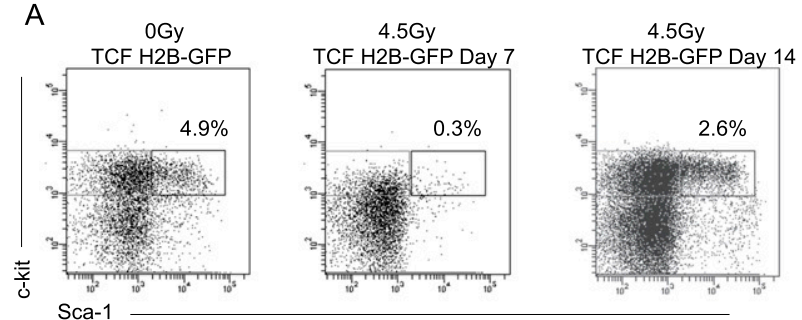

B

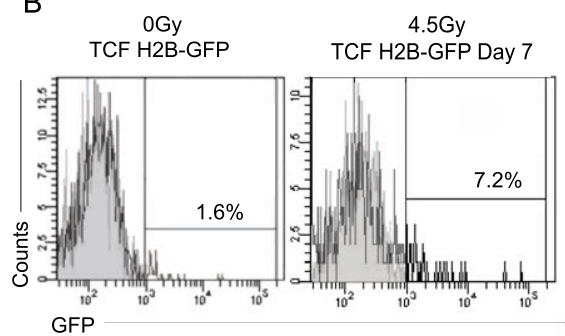
GFP
D

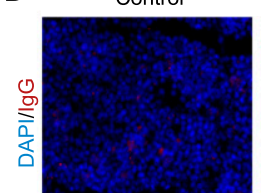

4.5Gy Irradiated

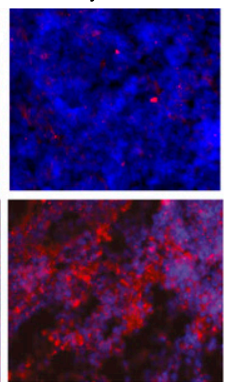

E

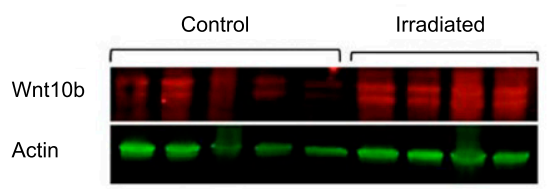

C

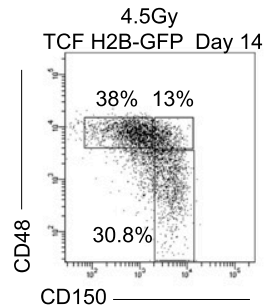

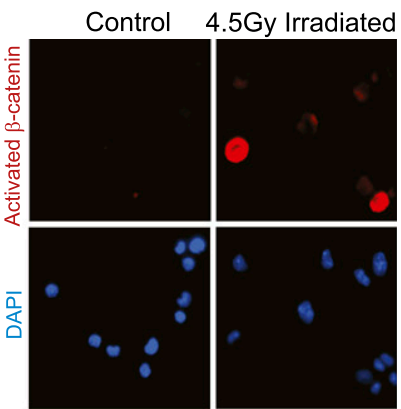

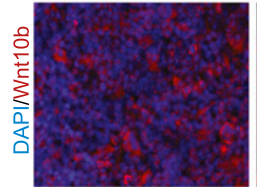

4.5Gy
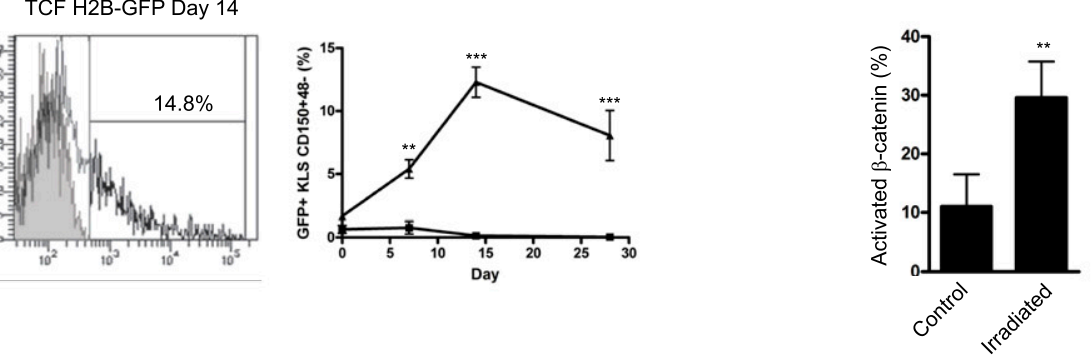

Figure 1. Hematopoietic injury activates Wnt signaling in hematopoietic stem and progenitor cells. (A) Representative FACS plots and GFP reporter expression of bone marrow KLS150 $48^{-}$stem cells from TCF/Lef H2B-GFP mice after 4.5 Gy. (B) Time course of reporter GFP induction in control (square) and TCF/Lef H2B-GFP (triangle) KLS150 $48^{-}$cells following exposure to a single dose of 4.5 Gy (day 0, $n=11-13$ per genotype; day 7, $n=7-9$ per genotype; day $14, n=6-12$ per genotype; day $28, n=5-9$ per genotype). Minimal autofluorescence signal is detected in the control cells. (C) Immunofluorescence staining and quantitation of activated (nonphosphorylated) $\beta$-catenin in irradiated $\mathrm{KLS}^{-}$cells $7 \mathrm{~d}$ after $4.5 \mathrm{~Gy}$. $(D)$ Representative immunofluorescence staining of Wnt10b expression in bone marrow sections from control and $4.5 \mathrm{~Gy}$ irradiated mouse femurs $7 \mathrm{~d}$ after radiation. Wnt10b is shown in red, and nuclei are stained with DAPI in blue $(n=3)$; control is matched IgG. $(E)$ Expression analysis of Wnt10b protein by immunoblotting whole bone marrow from control and irradiated mice on day 7 . The normalized Wnt $10 \mathrm{~b}$ levels are quantitated $(N=4-5$ mice per group). $\left.\left.\left(^{\star}\right) P<0.05 ;{ }^{\star \star}\right) P<0.01 ;{ }^{\star \star \star}\right) P<0.001$.

\section{Genetic loss of $\beta$-catenin impairs stem cell regeneration}

To address whether Wnt signaling may be required for recovery of the hematopoietic system after radiation injury, we used a loss-of-function mouse model in which exons 2 and 6 of the $\beta$-catenin gene are flanked by loxP sites (Brault et al. 2001). $\beta$-Catenin ${ }^{\mathrm{fl} / \mathrm{fl}}$ mice were crossed to mice in which Cre recombinase was expressed under the control of vav regulatory elements. Cre driven by the $v a v$ promoter mediates deletion of floxed sequences in the hematopoietic compartment, including in primitive fractions (de Boer et al. 2003; Almarza et al. 2004). In addition, we previously confirmed that $\beta$-catenin deletion occurs efficiently in HSCs harvested from these conditional $\beta$-catenin ${ }^{-1-}$ mice (Zhao et al. 2007). $\beta$-Catenin ${ }^{-/-}$mice were exposed to radiation, and their HSCs were isolated and plated in vitro to analyze cell growth. The loss of $\beta$-catenin led to impaired proliferation and a failure to maintain the stem and progenitor cell pool upon exposure to radiation (Fig. 2A,B). In addition, while the primary colony-forming ability of HSCs from control and $\beta$-catenin ${ }^{-/-}$mice was equivalent, $\beta$-catenin-null HSCs harbored significant defects in colony formation after serial replating (Fig. 2C). To test whether deletion of $\beta$-catenin affected survival after radiation injury, we analyzed apoptosis in control and $\beta$-catenin ${ }^{-1-}$ stem and progenitor cells (KLS) at 6 and $24 \mathrm{~h}$ after radiation. $\beta$-Catenin deficiency appeared to affect survival only minimally. Differences were not detected in the frequency of apoptotic stem cells (Annexin- $\mathrm{V}^{+}$propidium iodide ${ }^{-}$) at $6 \mathrm{~h}$, although an increase in necrotic or late apoptotic cells 
A

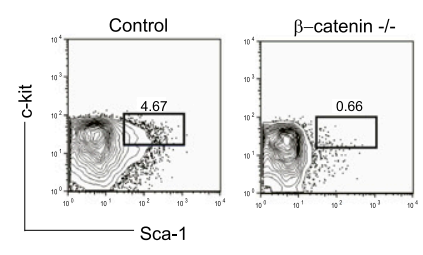

$B$

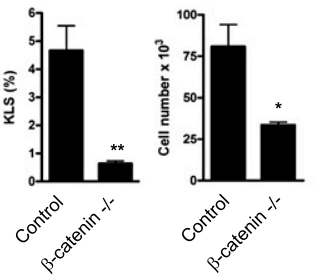

C

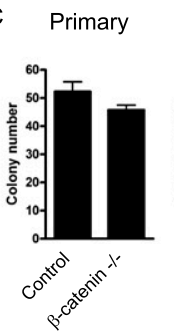

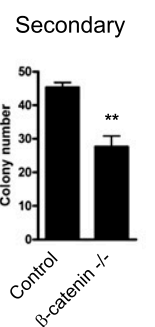

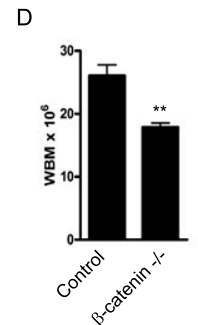

E

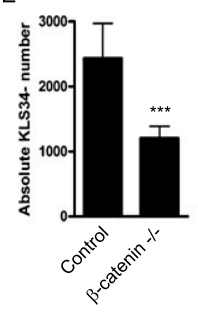

F

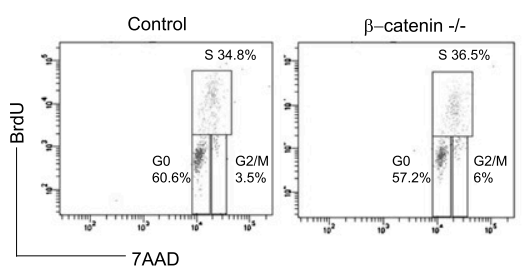

G

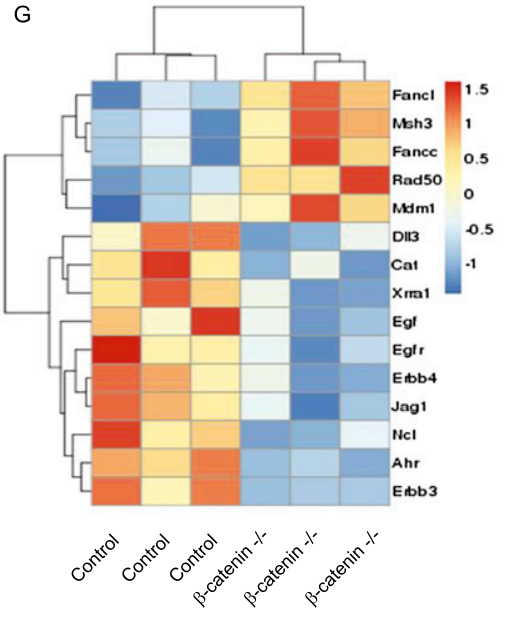

$\mathrm{H}$

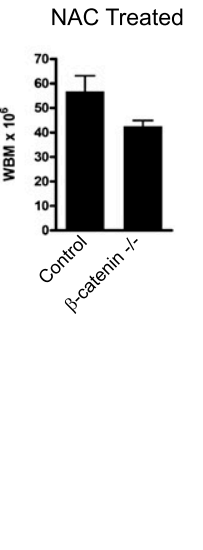

NAC Treated

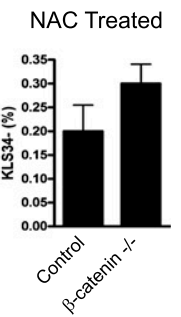

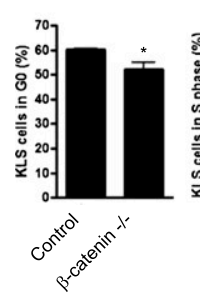
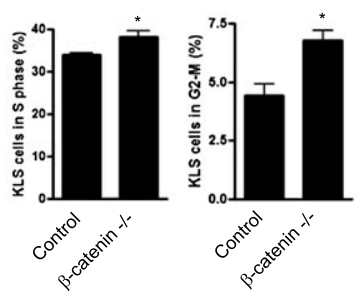

Figure 2. Loss of $\beta$-catenin impairs HSC function after radiation exposure. $(A, B)$ Representative FACS plots of in vitro cultured KLS34 ${ }^{-}$stem cells isolated from $4.5 \mathrm{~Gy}$ irradiated control and $\beta$-catenin ${ }^{-1-}$ animals $\left(n=4\right.$ per genotype). $\left({ }^{\star}\right) P<0.05 ;\left(^{\star \star}\right) P<0.005$. $(C)$ Colony formation of irradiated and sorted KLS34- cells in primary and secondary plating assays in methylcellulose medium. $\left(^{\star \star}\right) P<$ $0.01(n=3$ per genotype). $(D)$ Whole bone marrow counts at day 28 from mice irradiated with 4.5 Gy on day 0 and day $14(n=11$ per genotype). $\left(^{\star \star}\right) P<0.01$. (E) Absolute number of KLS34 ${ }^{-}$cells from mice in $D\left(n=10\right.$ per genotype). $\left(^{\star \star \star}\right) P<0.001$. $(F)$ Representative FACS plots and quantitation of in vivo BrdU labeling for cell cycle analysis on day 14 after 4.5 Gy $(n=3)$. $\left(^{\star}\right) P<0.05$. $(G)$ Heat map obtained from microarray analysis of gene expression in sorted KLS34 ${ }^{-}$stem cells from control and $\beta$-catenin ${ }^{-/-}$animals. $(H) \mathrm{N}$-acetylcysteine (NAC) treatment of mice irradiated with $4.5 \mathrm{~Gy}$ on day 0 and day 14 . NAC was given by oral gavage from day 15 to 28 , and the animals were sacrificed on day 35. NAC rescues bone marrow cell number, absolute KLS34- number, and KLS34 ${ }^{-}$frequency.

was noted (Supplemental Fig. S3A,B). Furthermore, no differences in either apoptosis or necrosis were seen at $24 \mathrm{~h}$ (Supplemental Fig. S3C,D).

To test whether loss of $\beta$-catenin had an impact on the regenerative capacity of HSCs in vivo after radiation, we tracked the recovery of control and $\beta$-catenin ${ }^{-1-}$ mice following sequential 4.5 Gy exposures on day 0 and day 14 as a strategy to increase the level of hematopoietic stress. $\beta$-Catenin ${ }^{-1-}$ animals displayed a significant reduction in the total bone marrow cellularity after radiation compared with controls $\left(17.8 \times 10^{6}\right.$ to $\left.26.08 \times 10^{6}\right)($ Fig. $2 D)$ and showed a twofold reduction in HSCs (Fig. 2E). These data suggest that $\beta$-catenin-mediated Wnt signaling is required in vivo to replenish the stem cell pool following radiation injury. Finally we tested whether the loss of $\beta$-catenin affected the cell cycle in regenerating cells in vivo using BrdU. $\beta$-Catenin ${ }^{-1-}$ stem and progenitor cells showed prolonged cycling, with an increased number of cells in both $S$ phase and G2-M phase after radiation (Fig. $2 F$ ). These data collectively indicate that loss of $\beta$-catenin leads to defects in stem cell growth and proliferation and impairs hematopoietic recovery after radiation.

\section{$\beta$-Catenin deficiency leads to increased $\mathrm{ROS} / \mathrm{O}_{2}{ }^{-}$ production and DNA damage}

To understand the molecular basis of the defects observed in $\beta$-catenin-deficient stem cells, we performed a genome-wide expression analysis of stem cells from control and $\beta$-catenin ${ }^{-/-}$mice. Due to the paucity of cells that can be recovered from irradiated mice, we tested gene expression differences in unirradiated stem cells. We first confirmed that $\beta$-catenin-deficient stem cells had the expected mRNA reductions compared with control cells. Consistent with the five exons bounded by loxP sites in the $\beta$-catenin locus, we found five probe sets differentially down-regulated with a 52 -fold median reduction of $\beta$-catenin (range 5.7-fold to 110-fold) (Supplemental Fig. S3E). Additionally, hierarchical analysis showed that stem cells from both genotypes clustered together, suggesting that $\beta$-catenin deletion did not have a general impact on housekeeping genes (Supplemental Fig. S3F).

Bioinformatics analysis revealed $\sim 2500$ differentially regulated probe sets $(P<0.05)$ with a fold change of \pm 1.5 and 688 with a fold change of \pm 2.0 (see Supplemental 
Table 1). This set of genes included several implicated in self-renewal and regeneration. For example, loss of $\beta$-catenin led to a significant twofold to threefold down-regulation of EGF and EGFR (Doan et al. 2013), Jag1 (Neves et al. 2006), Xray radiation resistance associated 1 (Xrra-1) (Mesak et al. 2003), and the Aryl hydrocarbon receptor (Ahr) (Casado et al. 2011). Interestingly, the deletion of $\beta$-catenin triggered a down-regulation of catalase (Fig. 2G), an enzyme critically important in protecting cells from oxidative damage by oxygen free radicals generically known as ROS. Because the generation of ROS is a known consequence of radiation damage (Wang et al. 2010), we tested whether the defects in $\beta$-catenin ${ }^{-1-}$ cells may be caused by decreased ROS clearance. We delivered the ROS scavenger $\mathrm{N}$-acetyl-cysteine (NAC) into irradiated control and $\beta$-catenin ${ }^{-1-}$ mice from day 14 to 28 (Fig. $2 \mathrm{H}$ ). Remarkably, in vivo NAC treatment rescued the defect in bone marrow regeneration and allowed complete recovery of HSCs in irradiated $\beta$-catenin ${ }^{-/-}$mice (Fig. 2H).

Because increased ROS levels have been shown to impair HSC self-renewal (Ito et al. 2006; Tothova et al. 2007), we directly tested whether HSCs accumulated ROS in the absence of $\beta$-catenin. Using the ROS-inducing agent pyocyanin, which causes accumulation of $\mathrm{H}_{2} \mathrm{O}_{2}$ (Muller 2002), as a positive control, we found that loss of $\beta$-catenin led to a 3.8-fold increase in $\mathrm{ROS}$ and $\mathrm{O}_{2}{ }^{-}$-positive stem and progenitor cells following radiation (Fig. 3A-C). Additionally, total ROS generation was also increased in purified stem cells (Fig. 3D; Supplemental Fig. S4A-C). ROS production was equivalent in control and $\beta$-catenin ${ }^{-/-}$cells in the absence of radiation (Supplemental Fig. S4D) as well as in irradiated $\mathrm{CD}^{+} \mathrm{T}$ cells, $\mathrm{CD} 19^{+} \mathrm{B}$ cells, and $\mathrm{Mac}-1^{+} \mathrm{Gr}-1^{+}$ myeloid cell populations (Supplemental Fig. S5A-C). These data suggest that loss of $\beta$-catenin specifically sensitizes stem and progenitor cells to the generation of oxidative stress molecules after radiation injury.

Because the generation of ROS and $\mathrm{O}_{2}{ }^{-}$following radiation can lead to the development of DNA lesions such as DNA double-strand breaks (Ward et al. 1987; Dong et al. 2011), we analyzed $\gamma$-H2A.X foci in irradiated stem cells from control and $\beta$-catenin ${ }^{-1-}$ mice. $\beta$-Catenin ${ }^{-1-}$ HSCs contained significantly more DNA breaks after radiation damage relative to control HSCs (Fig. 3F), consistent with 53BP1 staining (data not shown). There was no significant difference in the average number of $\gamma$-H2A.X lesions in the absence of radiation exposure (Fig. 3E). Consistent with rescue of bone marrow recovery after NAC treatment, the increase in DNA breaks that occurred in the absence of $\beta$-catenin could be effectively rescued by the in vivo delivery of NAC prior to radiation exposure /data not shown). These data collectively indicate that $\beta$-catenin deficiency impairs ROS regulation and DNA repair, which may in turn contribute to defects in regeneration.

\section{Loss of $\beta$-catenin disables regeneration after exposure to the chemotherapeutic agent 5-FU}

To test whether $\beta$-catenin is required specifically for repair following radiation or is also necessary for regeneration after other injuries, we focused on hematopoietic regener- ation after delivery of the chemotherapeutic drug 5-FU. 5FU is a clinically used myelosuppressive agent that effectively ablates proliferating hematopoietic progenitor cells and induces stem cell expansion and regeneration. To define whether $\beta$-catenin plays a role in recovery after 5FU injury, control and $\beta$-catenin-null mice were serially exposed to 5 -FU on day 0 and day 7 , and bone marrow and HSCs were analyzed at day 14. 5-FU exposure led to a significant decrease in total bone marrow cellularity in $\beta$-catenin ${ }^{-/-}$mice relative to control (Fig. 4A,B). Furthermore, the absolute numbers of long-term HSCs and multipotent progenitor $2\left(\mathrm{KLS}_{150}-48^{+}\right)$and multipotent progenitor $1\left(\mathrm{KLS}_{150^{+}} 48^{+}\right)$populations were significantly decreased in $\beta$-catenin ${ }^{-1-}$ bone marrow (Fig. 4C-F; Reavie et al. 2010). 5-FU treatment led to a multilineage defect in the generation of mature cells in the peripheral blood of $\beta$-catenin ${ }^{-/-}$mice, including total white cells, lymphocytes, neutrophils, and platelets (Fig. 4G-J). Finally $\beta$-catenin ${ }^{-1-}$ cells had significantly less Cyclin D1 and Axin 2 gene expression after injury (Fig. 4K), which served as a control for down-regulation of Wnt signaling in the absence of $\beta$-catenin.

To determine whether HSCs from 5-FU-treated $\beta$-catenin ${ }^{-1-}$ mice showed a functional inability to reconstitute long-term hematopoiesis, we performed both primary (Fig. 5A,B) and secondary competitive transplants. While control mice showed an average chimerism of $80.9 \%$, mice transplanted with $\beta$-catenin ${ }^{-/-}$ HSCs showed a significantly reduced average chimerism of $35.6 \%$ (Fig. 5C,D). Twenty-four hours after 5-FU injury, $\beta$-catenin ${ }^{-/-}$KLS cells had a significantly increased level of $\mathrm{O}_{2}{ }^{-}$generation (Fig. 5E), suggesting a potentially parallel mechanism of increased oxidative stress. Finally, the loss of $\beta$-catenin led to a striking inability to survive repeated stress. Thus, while $89 \%$ of control mice survived repeated 5-FU exposure (Sugiyama et al. 2006), only 40\% of the $\beta$-catenin ${ }^{-1-}$ mice survived this treatment (Fig. $5 \mathrm{~F}$ ). The finding that $\beta$-catenin is essential for surviving serial chemotherapy exposure has significant clinical implications, as repeated delivery of chemotherapy is routine in the context of cancer therapy. Thus, these data collectively suggest that $\beta$-catenin signaling is a critical element of effective hematopoietic regeneration after chemotherapy and raise the possibility that modulation of this pathway may improve recovery and outcomes after such treatment.

\section{Discussion}

Although effective regeneration is a key element of recovery after damaging clinical therapies, very little is known about the molecular mechanisms underlying this process. The results that we report here demonstrate that the Wnt signaling pathway is activated following systemic hematopoietic injury and implicate $\beta$-catenin as a critical regulator of hematopoietic regeneration after damage. Specifically, we show using genetic models that loss of $\beta$-catenin impairs the regeneration of irradiated HSCs in vitro and in vivo. Furthermore, as part of the mechanism underlying these defects, we show that 

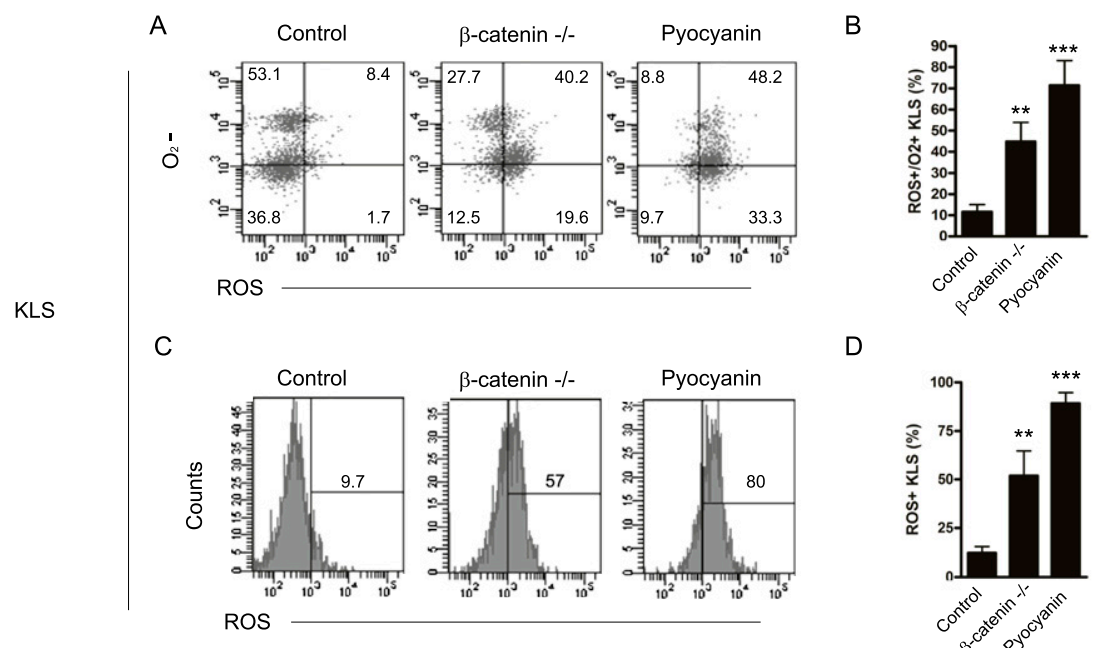

D
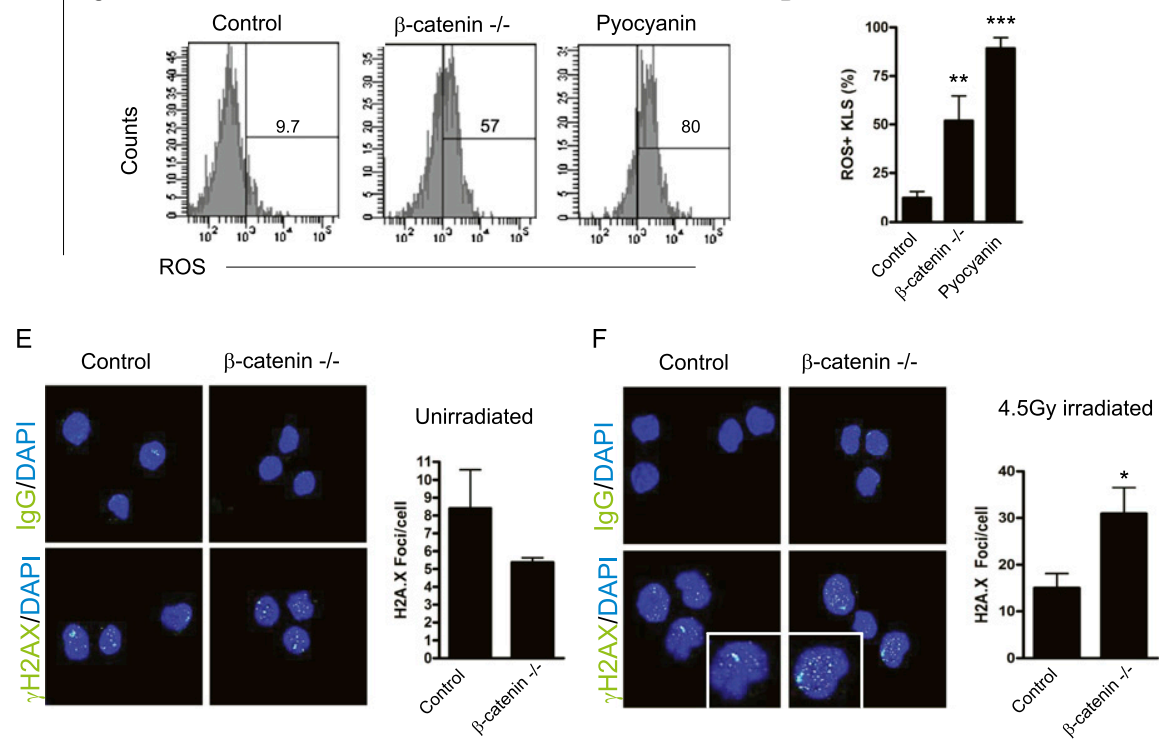

Figure 3. Loss of $\beta$-catenin potentiates ROS generation and impairs DNA double-strand break repair. $(A)$ Representative FACS plots of ROS and $\mathrm{O}_{2}{ }^{-}$in KLS cells from $4.5 \mathrm{~Gy}$ irradiated control and $\beta$-catenin ${ }^{-1-}$ animals isolated $1 \mathrm{~h}$ after irradiation. $(B)$ Quantitation of ROS and $\mathrm{O}_{2}{ }^{-}$double-positive KLS cells in $\left.\left.A .{ }^{\star \star \star}\right) P<0.005 ;{ }^{\star \star \star \star}\right) P<0.001$ compared with control cells. $(C)$ Representative FACS histograms of ROS in irradiated KLS cells. $(D)$ Quantitation of ROS in $C .\left(^{\star \star}\right) P<0.01 ;\left(^{\star \star \star}\right) P<0.001$. Pyocyanin served as a positive control for induction of ROS $\left(n=4-6\right.$ per genotype). $(E, F) \gamma$-H2A.X foci in unirradiated $(E)$ or 4.5 Gy irradiated $(F)$ KLS34 $4^{-}$cells from control and $\beta$-catenin ${ }^{-/-}$animals. The inset is bounded by white lines. Approximately $20-80$ cells were scored per sample $\left(n=6\right.$ per genotype). $\left({ }^{\star}\right) P<$ 0.05. See also Supplemental Figures S4 and S5.

$\beta$-catenin deficiency leads to increased oxidative stress and DNA double-strand breaks following radiation injury. The fact that bone marrow and peripheral blood regeneration was also impaired in $\beta$-catenin-deficient mice following exposure to the chemotherapeutic agent 5 -FU suggests that $\beta$-catenin is required for proper regeneration in response to a broad array of injuries.

A series of loss- and gain-of-function studies suggest that Wnt signaling plays a role in hematopoiesis under homeostatic conditions. The analysis of Wnt-3a-null embryos demonstrated that the loss of Wnt signaling led to impaired HSC renewal (Luis et al. 2009). Additionally, while Vav-driven embryonic deletion of $\beta$-catenin allows establishment of HSCs, it impairs their functional ability in transplantation assays (Zhao et al. 2007). In the context of these findings, the fact that $\mathrm{Mx}$-Cre-driven adult deletion of $\beta$-catenin singly or in combination with deletion of $\gamma$-catenin does not impair homeostatic hematopoiesis (Koch et al. 2008) suggests that either the timing or method of deletion can lead to differing outcomes. Additionally, Wnt signaling remains active in these double-mutant mice, raising the alternative possibility that incomplete deletion or compensatory pathways may contribute to the lack of an observable phenotype (Jeannet et al. 2008). Gain-of-function studies have also implicated Wnt signaling in the regulation of the hematopoietic system. Dosage experiments using combinations of hypomorphic APC alleles have shown that a low level of Wnt activation effectively expands functional HSCs, while excessive Wnt activity impairs self-renewal (Luis et al. 2011). Finally, analysis of an Mxl-Cre-driven constitutively active $\beta$-catenin knock-in mouse demonstrated that continuous Wnt signaling can impair stem cell differentiation and lead to overproliferation and HSC exhaustion (Kirstetter et al. 2006; Scheller et al. 2006). However, as none of these models tested the role of $\beta$-catenin in the context of injury, to the best of our knowledge, our work is the first to demonstrate a clear genetic requirement for canonical Wnt signaling in mammalian hematopoietic regeneration.

Several other signaling pathways have been implicated in hematopoietic regeneration primarily through gain-of-function studies. For example, enhanced sonic hedgehog signaling in Patched heterozygous mice increases peripheral blood leukocyte repopulation after 5FU administration (Trowbridge et al. 2006). In addition to developmental pathways, activation of signals driven 

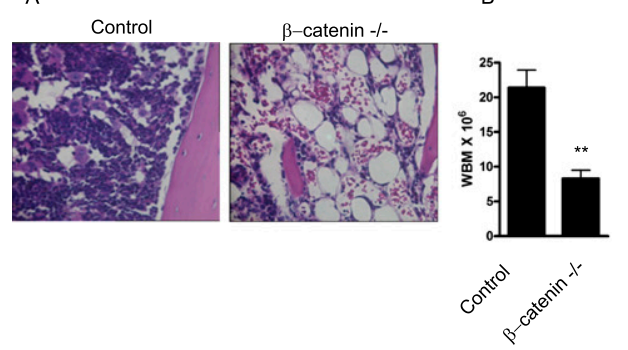

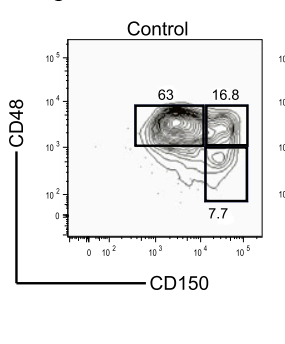

D

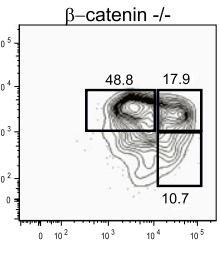

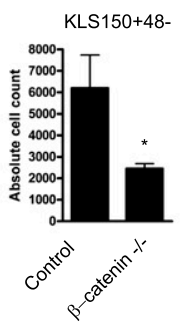

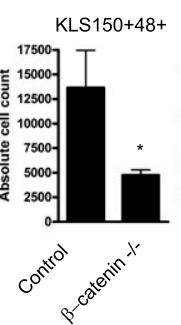

$\mathrm{F}$ KLS150-48+

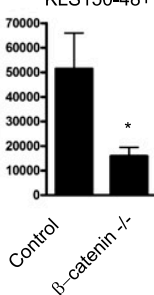

G

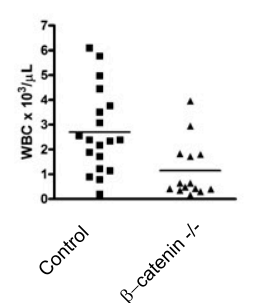

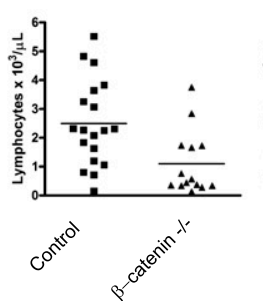
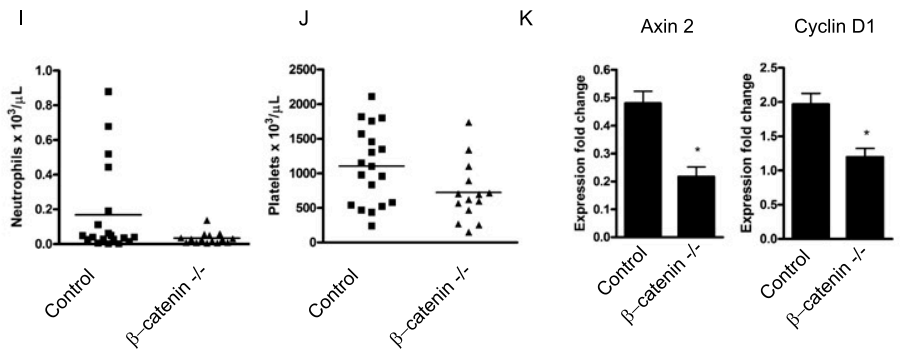

Figure 4. $\beta$-Catenin is required for hematopoietic regeneration following 5-FU treatment. (A) Representative H\&E-stained femur sections from control and $\beta$-catenin ${ }^{-1-}$ mice on day 14 after 5 -FU treatment $(120 \mathrm{mg} / \mathrm{kg})$ on day 0 and day $7(n=3)$. (B) Quantitation of whole bone marrow cells in 5-FU mice treated as described in $A\left(n=4-9\right.$ per genotype). $\left(^{\star \star}\right) P<0.01$. $(C-F)$ Representative FACS plots $(C)$ and absolute cell counts of KLS150 $48^{-}$long-term stem cells $(D)$, KLS150 $48^{+}$multipotent progenitor 1 cell populations $(E)$, and KLS150 $48^{+}$multipotent progenitor 2 cell populations $(F)$. The cells were pregated on live KLS cells $\left(n=4-9\right.$ per genotype). $\left({ }^{\star}\right) P=$ 0.05. $(G-J)$ Peripheral blood subsets from mice in $C(n=14-19$ per genotype). WBCs and lymphocytes $(P<0.01)$; neutrophils, and platelets $(P<0.05) .(K)$ Gene expression of Wnt target genes Axin 2 and Cyclin D1 after 5-FU injury by quantitative PCR $(n=3$ per genotype). $\left({ }^{\star}\right) P<0.05$.

by other growth factors have shown promise in enhancing hematopoietic regeneration. For example, in vivo delivery of Pleiotrophin, an endothelial cell-derived ligand (Himburg et al. 2010), can increase bone marrow and stem cell regeneration after radiation. Similarly, growth hormone has been identified as a soluble factor capable of enhancing hematopoietic regeneration and increasing animal survival following radiation damage (Chen et al. 2010). Whether these signals may be integrated during recovery or could be used in combination to improve regeneration will be an important question to address in the future.

Cells respond to oxidative stress by increasing the production of free radical scavengers such as manganese superoxide dismutase and catalase, FoxO family transcription factors, and modulators of DNA damage repair (Tran et al. 2002). The data that we report here show that loss of $\beta$-catenin augments the production of ROS and $\mathrm{O}_{2}{ }^{-}$in injured HSCs. Interestingly, the FoxO family of stress response transcription factors not only are critical regulators of HSC self-renewal (Miyamoto et al. 2007) but also have been shown to require $\beta$-catenin binding for transcriptional activity (Essers et al. 2005). While this raises an intriguing link between these signals, further studies are required to determine whether the regeneration defect is a direct consequence of reduced Wnt signaling or is also related to impaired FoxO transcription in response to oxidative stress. Our current data favor the direct involvement of Wnt signaling, as we did not detect a difference in FoxO3a activation between control and $\beta$-catenin-null HSCs (data not shown). However, whether FoxO-mediated transcription occurs effectively in regenerating $\beta$-catenin-null HSCs remains unclear. Future work analyzing the interactions of key transcription factors that integrate the stress response and self-renewal may lead to new approaches to accelerating HSC recovery and expansion in transplantation and regenerative medicine.

\section{Materials and methods}

\section{Mice}

The loxP- $\beta$-catenin and Vav-cre transgenic mice used were in the C57BL/6J background (Zhao et al. 2007). The TCF/Lef H2B-GFP mice were purchased from the Jackson Laboratory. All mice were bred and maintained on acidified water in the animal care facility at Duke University Medical Center. 5-FU was injected intraperitoneally at $120 \mathrm{mg} / \mathrm{kg}$ in PBS. Radiation was delivered by a Shepherd $\mathrm{Cs}^{137} \gamma$-irradiator at a dose rate of $6 \mathrm{~Gy} / \mathrm{min}$. All animal experiments were performed according to protocols approved by the Duke University Institutional Animal Care and Use Committee.

\section{Isolation and FACS of HSCs}

HSCs were sorted and analyzed from mouse bone marrow based on surface marker expression of c-Kit and Sca-1 and low to negative expression of lineage markers (Lin) and CD34 (KLS34 ${ }^{-}$)

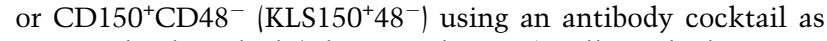
previously described (Zhao et al. 2007). All antibodies were purchased from Pharmingen or eBioscience. The cell analysis and cell sorting were performed on a FACSVantage cell sorter or 
Lento et al.

A

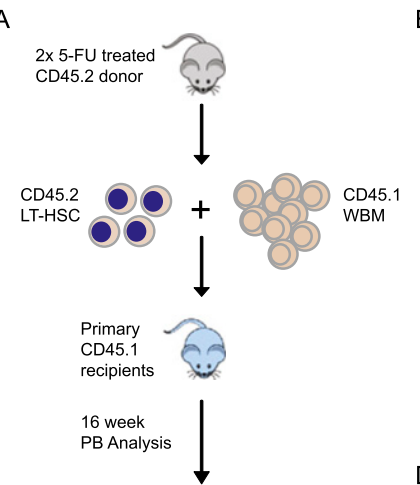

B

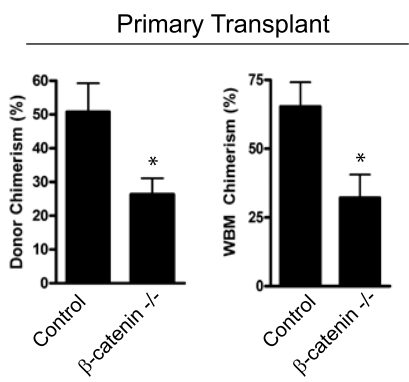

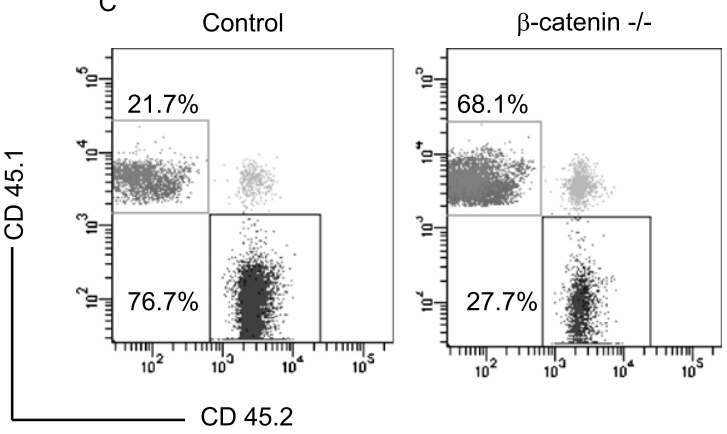

D

Secondary Transplant

Transplant WBM
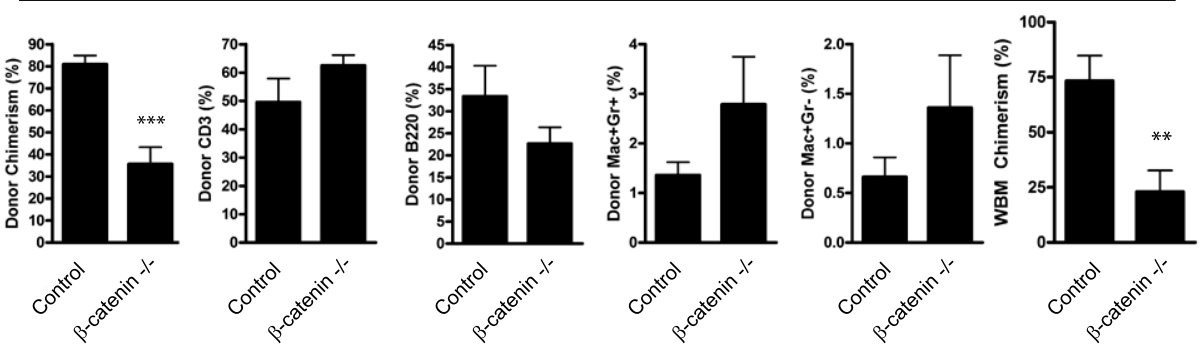

$\mathrm{E}$
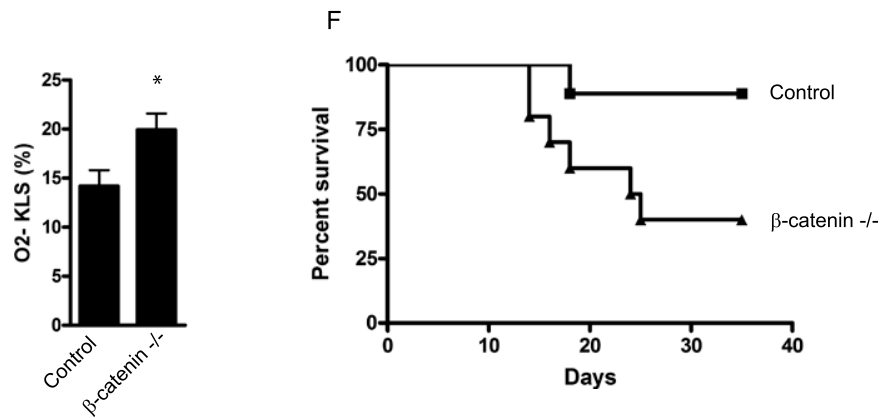

Figure 5. Loss of $\beta$-catenin impairs long-term HSC self-renewal following 5-FU treatment. $(A)$ Schematic for primary and secondary bone marrow transplants. Donor cells are CD45.2, and competitor cells are CD45.1. $(B)$ CD45.2 donor chimerism in the peripheral blood after the transplantation of 500 5-FU-treated KLS34- ${ }^{-}$cells at week 16 (left) and the bone marrow at week 18 (right) (n=6 recipients per genotype). $\left.{ }^{\star}\right) P<0.05 .(C)$ Representative FACS plots of peripheral blood after secondary bone marrow transplantation (week 16). The secondary recipients received $10^{6}$ whole bone marrow harvested from primary transplantation recipients sacrificed after $18 \mathrm{wk}$. $(D)$ Secondary transplantation peripheral blood chimerism and lineage subsets at $16 \mathrm{wk}(n=8-10$ recipients per group) and bone marrow chimerism at $20 \mathrm{wk}\left(n=7\right.$ per group). $\left(^{\star \star}\right) P<0.01 ;\left(^{\star \star \star}\right) P<0.0005$. (E) Frequency of $\mathrm{O}_{2}{ }^{-}$-positive KLS cells $18 \mathrm{~h}$ after treatment with $120 \mathrm{mg} / \mathrm{kg} 5$-FU $\left(n=7\right.$ per genotype). $\left(^{\star}\right) P<0.05(F)$ Kaplan-Meier plot of control and $\beta$-catenin ${ }^{-/-}$mice treated with $120 \mathrm{mg} / \mathrm{kg} 5$ FU on days 0,7 , and 14 ( $n=9-10$ mice per group). $P<0.05$.

CANTO analyzer (Becton Dickinson). For whole bone marrow analysis, $1 \times 10^{6}$ cells were stained with KLS34 or KLS150 $48^{-}$ as described (Reavie et al. 2010). Annexin-V apoptosis assays were performed by staining cells with Annexin-V and 7-AAD or propidium iodide (BD Biosciences).

\section{In vitro proliferation and methylcellulose assays}

For liquid culture, freshly sorted KLS34- ${ }^{-}$cells from irradiated control or $\beta$-catenin ${ }^{-1-}$ mice were plated in medium (X-Vivo15, Lonza) supplemented with $50 \mu \mathrm{M} 2$-mercaptoethanol, $2 \%$ FCS and SCF $(50 \mathrm{ng} / \mathrm{mL})$ and Flt-3L $(30 \mathrm{ng} / \mathrm{mL})$, and penicillin/ streptomycin. After culturing for the indicated time, the cells were counted for total live cells by Trypan blue exclusion. For methylcellulose assays, KLS34- ${ }^{-}$cells were plated in complete methylcellulose medium (StemCell Technologies, catalog no. M3434). The colony numbers were counted 8-10 d after plating.
Subsequently, the cells were harvested, counted, and replated for secondary colony formation.

\section{Immunofluorescence staining of cytospins and bone sections}

Freshly purified KLS34- ${ }^{-}$cells were sorted by FACS, and cytospins were fixed in $4 \%$ paraformaldehyde. The slides were then washed in PBS $+0.1 \%$ Tween, blocked with $20 \%$ normal goat serum, and stained with mouse anti-active $\beta$-catenin (Upstate Biotechnology) or mouse IgG isotype control (BD Pharmingen). The slides were washed in PBS-Tween $(0.1 \%)$ and stained with donkey antimouse IgG-TRITC (Jackson ImmunoResearch) or IgG-Alexa Fluor 488 (Invitrogen). Cell images were taken with a Zeiss 410 Axiovert microscope. To evaluate nuclear $\gamma$-H2A.X and 53BP1 staining, cells were treated as described above and then stained with rabbit polyclonal antibody to phosphorylated H2A.X (Abcam) or 53BP1 and then washed and labeled with Alexa Fluor 
488 secondary antibody (Invitrogen). For bone staining, fresh bone specimens from control and irradiated mice were decalcified, infiltrated with sucrose, and embedded in OCT medium (TissueTek). The frozen sections were fixed in acetone, washed in PBS-T, and blocked with 20\% normal donkey serum (Jackson ImmunoResearch). The tissue sections were stained with anti-Wnt10b (Santa Cruz Biotechnology) or the appropriate isotype control followed by donkey anti-goat Alexa Fluor 594 (Invitrogen). The nuclear dye DAPI (Invitrogen) was included in all stains.

\section{Oxidative stress analysis}

To quantify the development of oxidative stress, whole bone marrow cells were stained for KLS or $\mathrm{KLS}_{150}+48^{-}$and then incubated with $\mathrm{ROS} / \mathrm{O}_{2}{ }^{-}$detection reagents according to the manufacturer's instructions (Enzo life Sciences). Cells were then analyzed by flow cytometry on a CANTO analyzer (Becton Dickinson).

\section{Immunoblotting}

Whole bone marrow cells were isolated from control nonirradiated mice or 4.5 Gy irradiated mice on day 7 . The cells were lysed in mammalian protein extraction reagent (Thermo Scientific) with protease inhibitors and sonicated before SDS-PAGE separation. The proteins were transferred to PVDF membranes and incubated with Wnt10b primary antibody (Santa Cruz Biotechnology) overnight at $4^{\circ} \mathrm{C}$. The cells were then incubated with secondary antibody for $1 \mathrm{~h}$ at room temperature before visualization on a LI-COR imager (LI-COR Biosciences). The Wnt10b signals were normalized to actin.

\section{Transplantation and chimerism analysis}

HSCs were sorted from $\beta$-catenin ${ }^{-/-}$or control mouse bone marrow treated with $120 \mathrm{mg} / \mathrm{kg}$ 5-FU. Briefly, c-Kit-positive cells were enriched by staining whole bone marrow with anti-CD117/cKit microbeads, and positively labeled cells were isolated by autoMACS cell separation (Miltenyi Biotec). KLS34- $4^{-}$cells were then sorted, and 500 stem cells (CD45.2) were injected with $3 \times 10^{5}$ competitor whole bone marrow (CD45.1) into lethally irradiated (split dose totaling $10 \mathrm{~Gy}$ ) recipient B6-CD45.1 (B6.SJL-Ptprc ${ }^{a}$ $\mathrm{Pepc}^{b}$ /BoyJ) mice via the retro-orbital sinus. For lineage analysis, peripheral blood cells were obtained by submandibular bleeding and diluted in $0.5 \mathrm{~mL}$ of $10 \mathrm{mM}$ EDTA in PBS. Next, $1 \mathrm{~mL}$ of $2 \%$ dextran was added to each sample, and red blood cells were depleted by sedimentation for $45 \mathrm{~min}$ at $37^{\circ} \mathrm{C}$. The remaining red blood cells were lysed using RBC lysis buffer (eBioscience) before staining for lineage markers. Throughout the transplantation period, recipient mice were evaluated daily for signs of morbidity and weight loss.

\section{Statistical analysis}

Two-tailed Student's $t$-tests and one-way ANOVA were used to determine statistical significance. A $P$-value $\leq 0.05$ was considered significant. Statistical significance was determined using GraphPad Prism 4 software.

\section{Acknowledgments}

We thank Dr. Mike Cook and Dr. Beth Harvat for cell sorting, and Dr. Ashley Lento for help with confocal microscopy. W.L. received support from T32 CA 059365, and T.I. is the recipient of a California Institute for Regenerative Medicine interdisciplinary stem cell training program fellowship. This work was also supported by National Institutes of Health (NIH) grant U19 AI 067798 awarded to N.C. as well as by a Leukemia and Lymphoma Society Scholar Award and NIH grants DK63031, AI067798, HL097767 and DP1 CA174422 awarded to T.R. W.L designed and analyzed experiments and performed a majority of the work. C.Z., T.I., J.R.H, L.R, S.P., and W.H provided experimental help. C.J and K.O. performed bioinformatics analysis on all microarray data. N.C and T.R. guided the project and provided advice on experimental design and analysis. W.L. N.C. and T.R. wrote the paper.

\section{References}

Almarza E, Segovia JC, Guenechea G, Gómez SG, Ramírez Á, Bueren JA. 2004. Regulatory elements of the vav gene drive transgene expression in hematopoietic stem cells from adult mice. Exp Hematol 32: 360-364.

Brault V, Moore R, Kutsch S, Ishibashi M, Rowitch DH, McMahon AP, Sommer L, Boussadia O, Kemler R. 2001. Inactivation of the $\beta$-catenin gene by Wnt1-Cre-mediated deletion results in dramatic brain malformation and failure of craniofacial development. Development 128: 1253-1264.

Canales MA, Hernandez-Navarro F. 2004. G-CSF or not G-CSF? That is the question. Bone Marrow Transplant 34: 557.

Casado FL, Singh KP, Gasiewicz TA. 2011. Aryl hydrocarbon receptor activation in hematopoietic stem/progenitor cells alters cell function and pathway-specific gene modulation reflecting changes in cellular trafficking and migration. Mol Pharmacol 80: 673-682.

Chen BJ, Deoliveira D, Spasojevic I, Sempowski GD, Jiang C, Owzar K, Wang X, Gesty-Palmer D, Cline JM, Bourland JD, et al. 2010. Growth hormone mitigates against lethal irradiation and enhances hematologic and immune recovery in mice and nonhuman primates. PLOS ONE 5: el1056.

de Boer J, Williams A, Skavdis G, Harker N, Coles M, Tolaini M, Norton T, Williams K, Roderick K, Potocnik AJ, et al. 2003. Transgenic mice with hematopoietic and lymphoid specific expression of Cre. Eur I Immunol 33: 314-325.

Doan PL, Himburg HA, Helms K, Russell JL, Fixsen E, Quarmyne M, Harris JR, Deoliviera D, Sullivan JM, Chao NJ, et al. 2013. Epidermal growth factor regulates hematopoietic regeneration after radiation injury. Nat Med 19: 295-304.

Dong Q, Oh J-E, Chen W, Kim R, Kim RH, Shin K-H, McBride WH, Park N-H, Kang MK. 2011. Radioprotective effects of Bmi-1 involve epigenetic silencing of oxidase genes and enhanced DNA repair in normal human keratinocytes. I Invest Dermatol 131: 1216-1225.

Essers MAG, de Vries-Smits LMM, Barker N, Polderman PE, Burgering BMT, Korswagen HC. 2005. Functional interaction between $\beta$-catenin and FOXO in oxidative stress signaling. Science 308: 1181-1184.

Ferrer-Vaquer A, Piliszek A, Tian G, Aho R, Dufort D, Hadjantonakis A-K. 2010. A sensitive and bright single-cell resolution live imaging reporter of Wnt/SZ-catenin signaling in the mouse. BMC Dev Biol 10: 121.

Himburg HA, Muramoto GG, Daher P, Meadows SK, Russell JL, Doan P, Chi J-T, Salter AB, Lento WE, Reya T, et al. 2010. Pleiotrophin regulates the expansion and regeneration of hematopoietic stem cells. Nat Med 16: 475-482.

Ito K, Hirao A, Arai F, Takubo K, Matsuoka S, Miyamoto K, Ohmura M, Naka K, Hosokawa K, Ikeda Y, et al. 2006. Reactive oxygen species act through p38 MAPK to limit the lifespan of hematopoietic stem cells. Nat Med 12: 446-451.

Jeannet G, Scheller M, Scarpellino L, Duboux S, Gardiol N, Back J, Kuttler F, Malanchi I, Birchmeier W, Leutz A, et al. 2008. Long-term, multilineage hematopoiesis occurs in the combined absence of $\beta$-catenin and $\gamma$-catenin. Blood 111: 142-149. 
Kawakami Y, Rodriguez Esteban C, Raya M, Kawakami H, Martí M, Dubova I, Izpisúa Belmonte JC. 2006. Wnt/ $\beta$-catenin signaling regulates vertebrate limb regeneration. Genes Dev 20: 3232-3237.

Kawano Y, Takaue Y, Mimaya J, Horikoshi Y, Watanabe T, Abe T, Shimizu Y, Matsushita T, Kikuta A, Watanabe A, et al. 1998. Marginal benefit/disadvantage of granulocyte colonystimulating factor therapy after autologous blood stem cell transplantation in children: results of a prospective randomized trial. Blood 92: 4040-4046.

Kirstetter P, Anderson K, Porse BT, Jacobsen SEW, Nerlov C. 2006. Activation of the canonical Wnt pathway leads to loss of hematopoietic stem cell repopulation and multilineage differentiation block. Nat Immunol 7: 1048-1056.

Koch U, Wilson A, Cobas M, Kemler R, MacDonald HR, Radtke F. 2008. Simultaneous loss of $\beta$-and $\gamma$-catenin does not perturb hematopoiesis or lymphopoiesis. Blood 111: 160-164.

Luis TC, Weerkamp F, Naber BAE, Baert MRM, de Haas EFE, Nikolic T, Heuvelmans S, De Krijger RR, van Dongen JJM, Staal FJT. 2009. Wnt3a deficiency irreversibly impairs hematopoietic stem cell self-renewal and leads to defects in progenitor cell differentiation. Blood 113: 546-554.

Luis TC, Naber BAE, Roozen PPC, Brugman MH, Haas EFEd, Ghazvini M, Fibbe WE, Dongen JJMv, Fodde R, Staal FJT. 2011. Canonical Wnt signaling regulates hematopoiesis in a dosage-dependent fashion. Cell Stem Cell 9: 345-356.

Mesak F, Osada N, Hashimoto K, Liu Q, Ng C. 2003. Molecular cloning, genomic characterization and over-expression of a novel gene, XRRA1, identified from human colorectal cancer cell HCT116Clone2_XRR and macaque testis. BMC Genomics 4: 32 .

Miyamoto K, Araki KY, Naka K, Arai F, Takubo K, Yamazaki S, Matsuoka S, Miyamoto T, Ito K, Ohmura M, et al. 2007. Foxo3a is essential for maintenance of the hematopoietic stem cell pool. Cell Stem Cell 1: 101-112.

Muller M. 2002. Pyocyanin induces oxidative stress in human endothelial cells and modulates the glutathione redox cycle. Free Radic Biol Med 33: 1527-1533.

Mulroy T, McMahon JA, Burakoff SJ, McMahon AP, Sen J. 2002. Wnt-1 and Wnt-4 regulate thymic cellularity. Eur I Immunol 32: 967-971.

Neven B, Leroy S, Decaluwe H, Le Deist F, Picard C, Moshous D, Mahlaoui N, Debré M, Casanova J-L, Dal Cortivo L, et al. 2009. Long-term outcome after hematopoietic stem cell transplantation of a single-center cohort of 90 patients with severe combined immunodeficiency. Blood 113: 4114-4124.

Neves H, Weerkamp F, Gomes AC, Naber BAE, Gameiro P, Becker JD, Lúcio P, Clode N, Van Dongen JJM, Staal FJT, et al. 2006. Effects of Delta1 and Jagged1 on early human hematopoiesis: correlation with expression of Notch signaling-related genes in CD34 ${ }^{+}$cells. Stem Cells 24: 1328-1337.

Ojeda E, Garcia-Bustos J, Aguado MJ, Quevedo E, Arrieta R, Jimenez V, Canales M, Hernandez-Navarro F. 1999. Is filgrastim as useless after peripheral blood stem cell transplantation for adults as it could be for children? Blood 93: 3565-3566.

Reavie L, Gatta GD, Crusio K, Aranda-Orgilles B, Buckley SM, Thompson B, Lee E, Gao J, Bredemeyer AL, Helmink BA, et al. 2010. Regulation of hematopoietic stem cell differentiation by a single ubiquitin ligase-substrate complex. Nat Immunol 11: 207-215.

Roncarolo M-G, Gregori S, Lucarelli B, Ciceri F, Bacchetta R. 2011. Clinical tolerance in allogeneic hematopoietic stem cell transplantation. Immunol Rev 241: 145-163.

Scheller M, Huelsken J, Rosenbauer F, Taketo MM, Birchmeier W, Tenen DG, Leutz A. 2006. Hematopoietic stem cell and multilineage defects generated by constitutive $\beta$-catenin activation. Nat Immunol 7: 1037-1047.
Sugiyama T, Kohara H, Noda M, Nagasawa T. 2006. Maintenance of the hematopoietic stem cell pool by CXCL12CXCR4 chemokine signaling in bone marrow stromal cell niches. Immunity 25: 977-988.

Tothova Z, Kollipara R, Huntly BJ, Lee BH, Castrillon DH, Cullen DE, McDowell EP, Lazo-Kallanian S, Williams IR, Sears C, et al. 2007. FoxOs are critical mediators of hematopoietic stem cell resistance to physiologic oxidative stress. Cell 128: 325-339.

Tran H, Brunet A, Grenier JM, Datta SR, Fornace AJ, DiStefano PS, Chiang LW, Greenberg ME. 2002. DNA repair pathway stimulated by the forkhead transcription factor FOXO3a through the Gadd45 protein. Protein Sci 296: 530-534.

Trowbridge IJ, Scott MP, Bhatia M. 2006. Hedgehog modulates cell cycle regulators in stem cells to control hematopoietic regeneration. Proc Natl Acad Sci 103: 14134-14139.

Venezia TA, Merchant AA, Ramos CA, Whitehouse NL, Young AS, Shaw CA, Goodell MA. 2004. Molecular signatures of proliferation and quiescence in hematopoietic stem cells. PLOS Biol 2: e301.

Wang Y, Liu L, Pazhanisamy SK, Li H, Meng A, Zhou D. 2010. Total body irradiation causes residual bone marrow injury by induction of persistent oxidative stress in murine hematopoietic stem cells. Free Radic Biol Med 48: 348-356.

Ward J, Evans J, Limoli C, Calabro-Jones P. 1987. Radiation and hydrogen peroxide induced free radical damage to DNA. Br J Cancer 55: 105-112.

Zhao C, Blum J, Chen A, Kwon HY, Jung SH, Cook JM, Lagoo A, Reya T. 2007. Loss of $\beta$-Catenin impairs the renewal of normal and CML stem cells in vivo. Cancer Cell 12: 528541. 


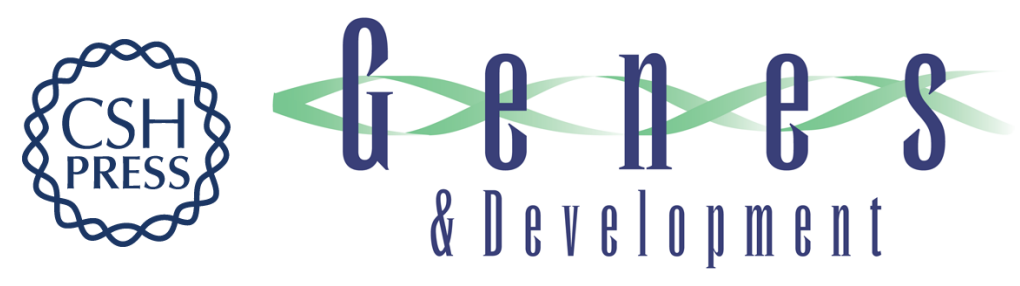

\section{Loss of $\beta$-catenin triggers oxidative stress and impairs hematopoietic regeneration}

William Lento, Takahiro Ito, Chen Zhao, et al.

Genes Dev. 2014, 28:

Access the most recent version at doi:10.1101/gad.231944.113

\section{Supplemental http://genesdev.cshlp.org/content/suppl/2014/04/29/28.9.995.DC1 Material}

References This article cites 37 articles, 11 of which can be accessed free at: http://genesdev.cshlp.org/content/28/9/995.full.html\#ref-list-1

Creative This article is distributed exclusively by Cold Spring Harbor Laboratory Press for the first Commons six months after the full-issue publication date (see

License http://genesdev.cshlp.org/site/misc/terms.xhtml). After six months, it is available under a Creative Commons License (Attribution-NonCommercial 4.0 International), as described at http://creativecommons.org/licenses/by-nc/4.0/.

Email Alerting Receive free email alerts when new articles cite this article - sign up in the box at the top Service right corner of the article or click here.

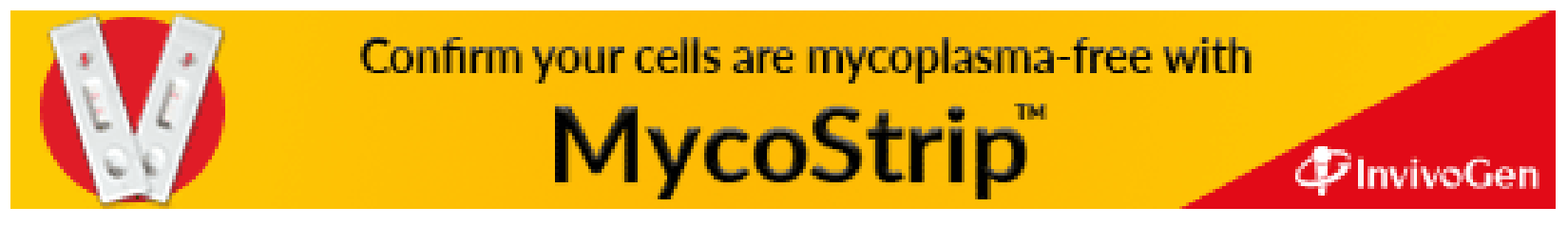

